\title{
EL DERECHO DE RESISTENCIA
}

Faustino Luna Farfannm

\section{Introducción}

Un pensador contemporáneo ha dicho con verdadero acierto, que el derecho de resistencia es invocada por las comunidades tiranizadas, al modo como el estado de necesidad es invocado por el Poder. Son recursos empleados en casos de verdadera excepcionalidad y fuera de la estabilidad calculable que el orden juridico supone. Toda revolución encuentra su justificación o condena más en la Historia que en el Derecho. Si fracasa, es una revuelta, configurada como delito; cuando triunfa, origina hechos juridicos a veces irreversibles. Ya en el siglo XVII, el jesuita Belarmino enseñaba:

"...depende de la multitud constituir un rey. unos cónsules o unos magistrados. $Y$ si se presenta una causa legitima, la multitud puede transformar una realeza en aristocracia o en democracia y viceversa. como leemos que se hizo en Roma. "Pero, -agrega-: "Jamàs el pueblo delega el poder hasta el punto de no conservarlo en potencia y poder, en ciertos casos. reasumirlo de hecho: "(De Laicis, libro III. Citado en lecturas de Derecho Constitucional, Pontificia Universidad Católica del Perú, 1962;167).

Santo Tomás de Aquino admite la licitud de la rebelión en contra de una tirania, del gobierno que no esté ordenado al bien común. León XIII. el Pontifice que con la Rerum Novarum pone la primera piedra de la doctrina social de la lglesia, declara en la Enciclica Libertas que "...cuando faita el derecho de mandar, o se manda algo contra la razón, contra la ley eterna, o los mandamientos divinos, es justo no obedecer a los hombres, se entiende, para obedecer a Dios".

El derecho de resistencia, como derecho natural del pueblo, a juzgar por las primeras referencias, y que autoriza a reaccionar colectivamente contra el abuso del poder público, alcanzó consagración constitucional con la Revolución Francesa, es decir, se convirtió en derecho positivo y que en el constitucionalismo peruano adopta el nombre de derecho de insurgencia, tiene los siguientes antecedentes juridicos.

1.- Antecedentes juridicos del derecho de resistencia:

- La Carta Magna, que el rey inglés Juan sin Tierra acepta en 1215, ya contiene en germen el derecho de insurgencia.

- En la Declaración de Independencia de los Estados Unidos se proclama que es derecho del pueblo alterar o abolir cualquier forma de gobierno que contradiga los derechos que al hombre ha otorgado el Creador.'

La doctrina De la declaración unănime de los Trece Estados Unidos de América (4 de julio de 1776) está expresado en los siguientes términos:

\section{*...sostenemos como verdades evidentes que todos los hombres nacen iguales: que a todos les confiere su Creador ciertos derechos inalienables entre los cuales están la vida, la libertad y la busca de la felicidad; que para garantizar estos derechos, los hombres instituyen gobiernos que derivan sus justos poderes del consentimiento de fos gobemados; que siempre que una forma de gobierno tiende a destruir esos fines, el pueblo tiene derecho a reformarla o abolina, a instituir un nuevo gobierno que se funde en dichos principios , y a organizar sus poderes en aquella forma que a su juicio garantice mejor su seguridad $y$ felicidad."}

- En el articulo 2 de la Declaración de los Derechos del Hombre y del Ciudadano de 26 de agosto de 1789 , que sirve de preámbulo a la Constitución de Francia, se lee; "El fin de toda asociación politica es la conservación de los derechos naturales e 
imprescriptibles del hambre. Esos derechos son la libertad, la propiedad, la seguridad y la resistencia a la opresión".

- La Ley Fundamental de la República Federal de Alemania, de 1949. (por citar un Estado emblemático por sus grandes crisis politicos y que experimentó el totalitarismo más exacerbado), con las enmiendas del 26 de noviembre del 2001 prescribe:

Art.20. Fundamentos del derecho estatal, derecho de resistencia: (...)

4. Contra cualquiera que intente dembar ese orden, les asiste a todos los alemanes ef derecho de resistencia cuando no fuera posible otro recurso".

Con estos antecedentes referidos a Estados emblemáticos por sus grandes cambios politicos, podernos decir que en todo Occidente. está reconocido el derecho de resistencia, y podemos afirmar sobre esa base, que ningún Estado de organización democrática, deja de reconocerlo ya expresa o ya tácitamente.

\section{EI derecho de resistencia en el constitucionalismo peruano}

En el constitucionalismo peruano, al derecho de resistencia se le llama derecho de insurgencia en las dos ulteriores Constituciones y tiene un unico antecedente en la Constitución de 1823, dada por José Bemardo Tagle, que en el Capitulo Primero y bajo el epigrafe de La Nación Peruana, establecía:

Art. IV. Si la nación no conserva o protege los derechos legítimos de todos los individuos que la componen, ataca el pacto social, asi como se extrae de la salvaguardia de este pacto cualquiera que viole alguna de las leyes fundamentales.

La Constitución de 1993, -aún vigente pese a habérsele retirado el nombre de Alberto Fujimori que la promulgó y en lo que al ejercicio del poder se refiere- reproduce en lo esencial el marco principista de la Constitución de 1979 inspirado en la doctrina Constitucional de Occidente en boga en los setentas del pasado siglo; asi es cómo el Articulo $45^{\circ}$ de nuestra Constitución declara:

"El poder del Estado emana del pueblo. Quienes 10 ejercen to hacen con las limitaciones y responsabilidades que la
Constitucion y las leyes establecen. Ninguna persona, organización, fuerza armada, policia nacional o sector de la población puede arrogarse el ejercicio de ese poder. Hacerio constituye rebelión a sediciōn"

Esta norma declarativa, está seguida por la del Articulo $46^{\circ}$, copiada casi literalmente el Articulo 82 de la Constitución de 1979, que previene la quiebra del orden constituido como premisa y reconoce el derecho de insurgencia, como su consecuencia, al disponer:

"Nadie debe obediencia a un gobierno usurpados ni a quienes asumen funciones públicas en violación de la Constitución y las leyes. La población civil tiene el derecho de insurgencia en defensa del orden Constitucional. Son nulos los actos de quienes usurpan funciones públicas".

El derecho de insurgencia en el Perú. considera Enrique Chirinos Soto, (1993: 292), es el primero de una serie de obstáculos juridicos que, en la letra de la ley, se oponen a futuros golpes de estado y futuros gobiernos usurpadores. Nadie debe a éstos obediencia. Se empieza por autorizar la desobediencia, siquiera la resistencia pacifica que practicó el Mahatma Ghandi y que terminó por expulsar a los ingleses de la India.

Refiere Chirinos Soto, que la paternidad intelectual def derecho de insurgencia incorporado en la Constitución de 1979. corresponde exclusivamente a Alfonso Ramos Alva ( del Partido Aprista), quien no cejó en la batalla hasta obtener la victoria. Contra el derecho de insurgencia, vencido una vez en el hemiciclo, se argumentó que concederlo al pueblo -el cual carece de armas- equivalía a concederlo a quienes las tienen, que son los militares: Entonces, Ramos Alva modificó la redacción para precisar que sólo podia ejercitarse ese derecho en defensa del orden constitucional, y no, por cierto, para abolirio. Ramos Alva alegó el hecho estadistico de que los paises que consagran especificamente el derecho a la insurgencia contra el usurpador como los Estados Unidos o la Gran Bretaña- no tienen golpes de estado. En cambio, los tienen los paises que no lo declaran, como el nuestro.

En un articulo publicado en una separata con el membrete de Asamblea Constituyente, 
bajo el título de El Derecho de Insurgencia, Recuerdo al Ideólogo, dice Ramos Alva:

"El derecho de insurgencia que se ha consagrado en el nuevo texto de la Carta Fundamental del Estado es diferente a la figura juridica de rebelión que confundió a muchos constituyentes. Mientras la rebelión viene a ser una acción violenta de un sector popular para derrocar a un gobierno constituido, sea de jure o de facto, el derecho de insurgencia que hemos propuesto. es la acción igualmente violenta de un sector o sectores populares no para defenestrar o derrocar, sino para defender a un régimen constitucional producto de la expresion soberana del sufragio. Con la rebelión se derroca a gobiemos tiránicos. con la insurgencia se defiende a un régimen constitucional."

Ahora parece tener explicación, el cómo los constituyentes de 1993, -surgidos del golpe de Estado de 1992 y con vocación continuista para lo que incorporaron a la Carta la reelección presidencial- reiteraran el derecho de insurgencia; es porque el derecho consagrado en la Constitución de 1993, se aparta de los postulados explicados por Belarmino, y los consagrados en la Declaración de Independencia de los Estados Unidos de Noreteamérica, sintetizados en el derecho de alterar o abolir y en el articulo 2 de la Declaración de los Derechos del Hombre y del Ciudadano de 26 de agosto de 1789 , del derecho de resistencia a la opresión. Es decir, consintieron en mantener una institución inocua.

La reiteración de la norma en análisis en la Constitución de 1993, segûn registra el Diario Expreso del 4 de mayo de 1993, fue motivo de "encendido debate de los congresistas Chirinos Soto, Carlos Torres y Torres Lara, Henry Pease. Carios Ferrero y Lourdes Flores, a partir de la premisa de que: la civilidad tiene el derecho de insurgencia en defensa del orden constitucional.

El Doctor Alfonso Ramos Alva, profesor de la Maestria de Derecho Constitucional de la Universidad Nacional Federico Villarreal, ha insistido siempre en sus lecciones, el sentido estrictamente defensivo del régimen constitucional del derecho de insurgencia instituido por su iniciativa.
Pero, en el pensamiento de Ferdinad Lasalle. "los problemas constitucionales, no son primordialmente problemas de derecho, sino de deber. la verdadera Constitución de un pais solo reside en los poderes reales que en ese pais rigen; las constituciones escritas no tienen valor ni son duraderas mas que cuando dan expresión fiel a los factores de poder imperantes en la realidad social; de otro modo, estas pueden calificarse de una simple hoja de papel. "(citado por Vladimiro Naranjo, 2000; 354)

Ya que la realidad determina que cuando un régimen, no obstante elegido en el marco constitucional deviene perverso y espurio; una norma tan vital para la preservación de la democracia no puede convertirse en letra muerta, o articulo de lujo, que existe pero no sirve. El caso es que estamos ante un problema de interpretación constitucional, algunos de cuyos principios esenciales son:

- La unidad de la Constitución

- La concordancia práctica

- La adaptación a las circunstancias

- La interpretación sistemática

- La interpretación extensiva y analógica, a los que los tratados de Derecho Constitucional dedican parte importante de su objeto y contenidos, como el del constitucionalista colombiano Viadimir Naranjo Mesa (ob.cit: 418).

De los principios interpretativos mencionados, el de la unidad constitucional, permite encontrar en el principio de la legitima defensa, -consagrada por el numeral 23, del Art. 2 de la vigente Constitución nacional-, en el pensamiento del penalista argentino Eugenio $R$. Zaffaroni, (2002: 617) involucramiento del derecho de insurgencia. Explica el autor:

-..tuvo lugar en el ámbito de los delitos de homicidio y lesiones y se extendió luego a otros bienes juridicos... de esta manera pasó a la parte general de los códigos, y más recientemente por efectos de dramáticas experiencias politicas, tiende a abarcar derechos que hacen a la autonomia pública de los habitantes reconociéndoles el derecho a la defensa del sistema 
democrático de gobierno. En la actualidad es unánime la opinión de que todo bien juridico es legitimamente defendible, aunque su lesión no sea relevante para el derecho penal. Esto está claro en la ley vigente, al expresar ésta que la defensa puede ser propia, de sus derechos de la persona o de los derechos de otro."

La cuestión se reduce entonces a saber, si la insurgencia es un derecho de defensa de la democracia. o es un derecho que queda restringido a la defensa del orden constitucional. como dice el Art. 46 de la constitución peruana. Y de la posible respuesta surge la siguiente cuestión: ¿corresponde a los habitantes de un pais defender el orden constitucional aunque les sea opresivo el régimen que gobiema? zo es que tal defensa corresponde en todo caso a los agentes públicos, que están por y para el régimen politico, cuya subsistencia les interesa como grupo, estos podrán ser por ejemplo los militares, por no ser deliberantes; no asi los congresistas cuyo origen y objeto es politico?

\section{El derecho de insurgencia y las restric- ciones para poseer y portar armas}

La vigencia del derecho de insurgencia, incluso del modo como ha sido concebido en las dos últimas constituciones peruanas, se vincula inmediatamente, o mas bien, está condicionada al derecho de poseer y portar armas, porque sin ese derecho, como sagazmente observó Chirinos Soto, resulta letra muerta el derecho de insurgencia proclamada por el Art. 46 de la Constitución peruana.

Pero tampoco basta la vigencia de uno y otro derecho, sino que su eficacia politica vaya de la mano con el adiestramiento del pueblo en el uso de las armas junto con el fortalecimiento de la conciencia ciudadana, que exige en primer lugar educar en el compromiso de servir en las fuerzas armadas como deber insosiayable, con el carácter general y obligatorio como funciona en los EE. UU de Norteamerica, donde como ya dijimos, todo ciudadano, -salvo el que esté afectado de alguna incapacidad especificacumple un periodo de servicio militar en cualquiera de sus fuerzas, con lo que de paso se diluye esa gran brecha mental entre civiles y militares en sus mutuas relaciones; porque a decir de Smith $(1969,329)$ :

"Al ingresar a las fuerzas armadas, el norteamericano no se desprende del ciudadano para convertirse en soldado. Los hábitos por la obediencia y respeto por la ley persisten..."

En el Perú, sin estar prohibido por la Constitución a los civiles el poseer y portar armas, el tono intimidante de la norma Constitucional que los regula, relativiza ese derecho:

Art. 175: "Sólo las fuerzas armadas y la Policia Nacional pueden poseer y usar armas de guerra (...) La ley reglamenta la fabricación, el comercio, la posesión, el uso, por los particulares, de armas distintas a las de guerra."

Si quienes califican cuándo un arma es de guerra", y aún su sola posesión, son funcionarios de los institutos armados; el civil tiene poco que argumentar en defensa de su derecho, y si ése derecho se vincula con la capacidad real de enfrentarse a los elementos armados que pretendan instalar o defiendan una dictadura, está perdido de antemano. Ulteriores reglamentaciones (Leyes $N^{\circ} 25054$ y 25403 y las leyes represivas que empezaron con el D. Leg. $N^{\circ} 761$ de noviembre de 1991 han dejado para uso civil en el Perú armas cortas que no deben exceder de los 9 milimetros de calibre y un alcance de fuego efectivo no mayor de treinta metros, y las armas largas reducidas finalmente a escopetas y rifles menores de caza, con prohibición expresa de las escopetas modificadas.

Segùn la estadistica publicada el 23 de abril del 2004 por el Ministerio del Interior, desde el año 1966 se habian otorgado en el Perú 270.041 licencias iniciales. En el año 1966 fueron 12.729 licencias, de las cuales 2,911 fueron para el uso de escopeta, 3,075 para pistola, 6,202 para revolver y 15 para escopeta o carabina de caza. totalizando con pocas variaciones anuales a! año 199879.626 licencias iniciales. A partir de ese año se produjo un inusual incremento hasta alcanzar la cifra record de 190,415 licencias a: 2004, con predominio de las armas cortas.

Por licencias iniciales debemos suponer que las licencias no fueron renovadas a la expiración del plazo (dos años) y aun podemos conjeturar que muchas de las armas fueron entregadas a Estado en el marco de las disposiciones punitivas, y las motivadas en la denuncia de posesiones llegales, en el marco de la legislación antisubversiva. La preferencia por la 
posesión de armas cortas se ha explicado en el incremento de la delincuencia urbana y la incapacidad de la autoridad para controlarla.

Otra inferencia que cabe hacer, es que el cuadro estadistico en su pico más alto. demuestra que poco menos del $2 \%$ de la población adulta peruana, -sobre un global estimada en 27 millones-, posee o ha poseido un arma, preferentemente arma corta. Este indice tan reducido se debe a la brevedad del plazo de las licencias y a la complicada reglamentación para obtenerlas, y seguramente las carencias económicas: pero sobre todo la cultura de la prohibición que está muy honda en nuestros espiritus. En otras palabras, la civilidad peruana está inerme frente al Poder público potencialmente opresivo y ante la delincuencia común, sea para defender sus derechos fundamentales, como son vida y sus posesiones. y para eventualmente alistarse y coadyuvar a la defensa de la patria ante las amenazas extemas: situación que encontraria a la población no sollo inerme, sino, sin adiestramiento.

\section{Armas del pueblo}

"De aqui que en un gobiemo democrático ejerzan supremo poder los militares, y los ciudadanos posean armas. "Aristóteles, Politica.

Bajo este titulo, Jorge Basadre (1989, Tomo IX: 48-49), da noticia de algunos episodios politicos que en el Perú y en Latinoamérica dieron ocasión a la civilidad, -generalmente fallida-, de poseer y portar armas y aun. propendieron a la formación de milicias civiles:

"Para sostener al gobiemo en las criticas circunstancias que surgieron a fines de enero de 1914, apareció la idea "de armar al pueblo", con el material existente en el arsenal militar de Santa Catalina. Según una información aparecida en la prensa a raiz de la revolución de 4 de febrero de 1914, llegó a ser firmado un Decreto por el cual el servicio de artilleria quedaba separado de la vigilancia del Jefe de Estado Mayor General. La misma información aseveró que el general Desvoyes, jefe de la misión mifitar francesa, dirigió al gobierno un oficio con el fin de manifestar que el asunto caia bajo su jurisdicción, que el buen criterio técnico imponia un sistema de dependencia entre el servicio de artilleria y el Estado Mayor que pedia la reconsideración del Decreto y que si ello no se hacia se diera por fenecido el contrato con dicha misión. Asi habria sido detenida de inmediato la medida proyectada, si bien podria luego ser puesta en la práctica con un jefe de estado mayor propicio al gobiemo.

Es muy probable que dentro del conjunto de los motivos que ocasionaron el pronunciamiento militar, el de evitar las milicias populares fuera uno de los más poderosos, como se verá en seguida, segûn afirmó Billinghurst en el documento que suscribió en Arica en octubre de 1914; ếl no llegó a decidirse a entregar las armas al pueblo, a pesar de las apremiantes instancias que recibió para que las hiciera."

El mismo Basadre dice, se dieron Casos latinoamericanos de armamentos del pueblo, como contrapeso al poder militar:

El intento de crear un contrapeso a la fuerza militar armando los sectores populares ha surgido recientemente en varios paises de Latinoamérica. Al efectuarse la revolución boliviana en 1952. las tropas policiales constituyeron un elemento importante dentro del partido vencedor, pero para mayor seguridad los trabajadores y los campesinos habian recibido armas también. Por otra parte en México en el periodo de Lázaro Cárdenas. se esbozó la politica de utilizarse a los sindicatos armados para contrabalancear el poder de los militares profesionales. Lo mismo trató de hacer Perón en el momento desesperado que precedió a su caida.

Semejantes medidas implican una anomalia dentro del régimen interior de un Estado, y en México y en Argentina las fuerzas armadas han podido recuperar su función institucional dentro de la colectividad: en el primero de esos paises se mantiene alejadas de la politica y su relieve económico y social disminuye, mientras que en el segundo de ellos se ha acentuado su poder: en cambio en Bolivia durante el tiempo en que estuvo el Movimiento Nacionalista Revolucionario en el poder se trato de mantener un balance precario entre. el ejèrcito reformado, las tropas policiales y las milicias campesinas y mineras. En este pais ha venido una restauración militarista. " 
La historia registrada por Basadre, dernuestra una vez más, que si los gobernantes del Perú pensaron alguna vez en armar al pueblo, fue generalmente en la coyuntura de los vaivenes del poder, salvo los casos latinoamericanos que parecieron obedecer a una politica de resistencia social a los procesos opresivos, o de autodeterminación frente a las potencias extranjeras como fue el caso de México con Lázaro Cárdenas. Con todo. los pocos ejemplos fueron episódicos y de breve duraciôn.

\section{Del derecho formal a la prohibición en- mascarada}

Terminada la guerra de independencia y cuando los caudillos militares convocaban a sus partidarios, sus antiguos subordinados, a echar mano a las armas con que habian combatido ahora defender a su caudillo, pareció conveniente prohibir el uso civil de la armas. Posteriores conflictos internos por grupos subversivos armados ha ahondado la conciencia de la prohibición; de alli a la conveniencia de mantener inerme al pueblo, ha sido de fácil trámite legislativo.

\section{La milicia}

Sólo los pueblos como el norteamericano. que forjaron su propia independencia primero. como milicia, después organizando un ejército permanente, luego paralelizando ambas fuerzas para la preservación de la primacia del poder civil, lo mantienen actualmente en la generalidad de sus Estados miembros, y aunque la corriente abolicionista crece, un sector numeroso y destacado de la sociedad estadounidense, propugna su preservaciôn.

A ese propósito, la Declaración de derechos de Virginia, aprobada el 12 de junio de 1776 , dejó establecido en su Art. XIII:

"Una milicia bien regulada, reclutada entre el pueblo, entrenada en el manejo de armas, es la defensa adecuada, natural, y segura de un Estado libre: los ejércitos permanentes en tiempo de paz deben evitarse como peligrosos para la libertad; y en todo caso las fuerzas armadas estarán bajo la estricta subordinación y gobierno del poder civit."

$Y$, cuando parecia que los constituyentes de 1787, habian omitido reiterar este principio, por la II enmienda se subsano su ausencia en la Constitución, al establecer:

"Siendo necesaria una milicia ordenada para la seguridad de un Estado libre no se violará el derecho del pueblo de poseer y portar armas."

La Constitución de Cádiz de corte liberal. consecuencia de la sublevación del pueblo madrileño el 2 de mayo de 1808 , con la acción eficaz de los guemilleros que inició la guerra de independencia contra las fuerzas francesas que se habian apoderado de territorio español aprovechando las disensiones internas de la monarquia, abolida después por el absolutismo y restaurada por una nueva sublevación en 1820 dispuso en su Art. 362: "Habrá en cada provincia cuerpos de milicias nacionales, compuesta de habitantes de cada una de ellas, con proporción a su población y circunstancias". Y, seguramente temiendo que las milicias se convirtieran en un mecanismo de resistencia, dispuso en su Art.364: "El servicio de esta milicia no será continuo y sólo tendrá lugar cuando las circunstancias lo requieran."

La Constitución mexicana de 1917, vigente, en su Art, 38 dispuso:

Los habitantes de los estados mexicanos tienen libertad de poseer armas de cualquier clase para su seguridad y legitima defensa...". Que unido al Art. 39 otorga el derecho de insurgencia real. La soberania nacional reside esencial y originariamente en el pueblo. Todo poder público dimana del pueblo y se instituye en beneficio de éste. El pueblo tiene en todo tiempo el inalienable derecho de alterar o modificar la forma de gobiemo."

Entre los textos constitucionales históricos: la Constitución francesa de 1791 estableció, los siguientes principios: 
Art. 107: "La fuerza general de la república está compuesta por el pueblo en su totalidad." Art. 109: "Todos los franceses son soldados, todos se ejercitan en el manejo de las armas. Art. 114: Ningün cuerpo armado puede deliberar."

$Y$ para no insistir en los contrastes, que nos forzaria a agrupar a los Estados en: otorgacionistas y abolicionistas, la Constitución española de 1978, reconoce en el capitulo: De los derechos y deberes de los ciudadanos, Art. 30.1:

"Los españoles tienen el derecho y el deber de defender a España. 30.2.- "La ley fijará las obligaciones militares de los españoles. con la excepción de concurrencia de causa de excensión militar obligatoria, pudiendo imponerse en su caso una prestación social sustitutoria:"

Por similar fórmula ha optado la República Federal de Alemania en su Ley Fundamental de 1949 con las modificaciones de noviembre del 2001:

Articulo 12. 1: Los varones que hayan cumplido los dieciocho años de edad pueden ser obligados a prestar servicios en las Fuerzas Armadas. En el cuerpo federal de protección de las fronteras o de una unidad de defensa civil."

Articulo 17.1: "En el caso de defensa, las personas sujetas al servicio militar que no fueran llamados a prestar uno de los servicios mencionados en los apartados 1 y 2 pueden ser obligados por ley o en virtud de una ley, dentro del marco de una relación laboral, a prestar servicios civiles con fines de defensa, incluyendo la protección de la población civil..."

Destacamos estos casos, porque nos parece que entre autorizar una milicia paralela o coordinada con los ejércitos permanentes, o marginar al pueblo de las necesidades de defensa, han optado por involucrar a la civilidad, con caracter obligatorio, en la defensa integral, en actividades que incluyen la preparación militar.

En resumen, y frente a esta situación, aceptamos provisoriamente la reflexión de Louis Smith: probablemente la mejor defensa reposa en el espiritu democrático del ciudadano más que en su capacidad para intimidar al gobierno por la fuerza de sus armas. El poco efecto disuasivo de las armas que los civiles podrian poseer por lo común, queda ampliado por el simbolismo del derecho en sí.

Con tales antecedentes, creemos que el derecho de insurgencia cobrara nitidez ideológica con la práctica que de el se haga, sin necesidad de una modificación de la norma constitucional que lo consagró.

\section{RESULTADOS, AMODO DE CONCLUSIONES}

1. En sus origenes, el derecho de resistencia fue invocado por las comunidades tiranizadas, al modo como el estado de necesidad es invocado por el Poder. Son recursos empleados en casos de verdadera excepcionalidad y fuera de la estabilidad calculable que el orden juridico supone. Toda revolución encuentra su justificación o condena más en la Historia que en el Derecho. Si fracasa, es una revuelta, configurada como delito: cuando triunfa, origina hechos juridicos a veces irreversibles.

2. Para fortalecer la capacidad defensiva del Estado, tanto ante peligros internos cuanto peligros externos, y darle efectiva capacidad de resistencia a los ciudadanos frente a los autoritarismos y las tiranias deben restituirse las milicias permanentes.

3. Junto con la milicia, la mejor defensa de la civilidad reposa en el espiritu democrático del ciudadano, más que en su capacidad para intimidar al gobierno por la fuerza de sus armas: pues, el poco efecto disuasivo de las armas que los civiles podrian poseer por lo comùn. queda ampliado por el simbolismo del derecho en si. 


\section{BIBLIOGRAFIA}

- BASADRE, G. Jorge.

1989. Historia de la República. Lima, Edit. Intern.

- CHIRINOS S., Enrique Francisco

1993 Constitución de 1993. Lima, Edit. NERMAN S.A.

- NARANJO M., Vladimiro

2000 Teoria Constitucional e Instituciones Politicas. Santa Fé de Bogotá, Edit. Temis

- SMITH, Louis

1965 La Democracia y el Poder Militar. B. Aires, Bibliografia Omeba

- ZAFAORINI, E. Raúl

2002 Derecho Penal, Parte General. B Aires, Edit. Ediar. 